\title{
Çocuk Çölyak Hastalarında Glutensiz Diyet ve Mikrobiyota Odaklı Tedavilerin İntestinal Mikrobiyotaya Etkisi*
}

\section{The Effect of Gluten-free Diet and Microbiota Focused Treatment on Microbiota Alterations in Children with Celiac Disease}

\author{
Yasemin Ertaş-Öztürk ${ }^{1}$ Efsun Karabudak ${ }^{2}$
}

Geliş tarihi/Received: 03.07.2019 • Kabul tarihi/Accepted: 29.08.2019

\section{ÖZET}

Çölyak hastalığı genetik yatkınlığı bulunan bireylerde gluten tüketimini izleyen dönemde ciddi gastrointestinal veya ekstraintestinal sistem bozuklukları ile seyreden ince bağırsağın bir hastalığıdır. Hastalığın patogenezinde genetik etmenlerin yanı sıra çevresel faktörlerin rol oynadığı düşünülmektedir. Son yıllarda intestinal mikrobiyotadaki değişimlerin çölyak hastalığının patogenezindeki yeri gösterilmeye ve potansiyel girişimsel olmayan tedaviler için ipuçları sağlanmaya çalışılmaktadır. Yapılan çalışmalar çölyağın aktif ve tedavi altındaki dönemlerinde mikrobiyota değişimleri olduğunu göstermektedir. Ancak, çölyağın tedavisinde kullanılan glutensiz diyetlerin de bu değişimlere katkıda bulunduğuna dair araştırmalar mevcuttur. Dolayısıyla, intestinal mikrobiyotanın modülasyonunda konakçı, diyet ve immün sistem etkileşimlerinin bir arada değerlendirilmesi gerekmektedir. Bu derleme ile çocuk çölyak hastalarında glutensiz diyet ve mikrobiyota odaklı tedavilerin intestinal mikrobiyotaya etkisi incelenmiştir.

Anahtar kelimeler: Çölyak hastalığl, mikrobiyota, glutensiz diyet, çocuk

\begin{abstract}
Celiac is a small intestine disease with severe gastrointestinal or extraintestinal disorders following gluten consumption in individuals with genetic predisposition. Along with genetic factors, environmental factors are thought to play a role in the pathogenesis of the disease. In recent years, the role of alterations in intestinal microbiota in the pathogenesis of celiac disease has been shown and clues have been provided for potential non-invasive treatments. Studies show microbiota alterations during active and treatment periods of celiac. However, there is evidence showing that gluten-free diets may also contribute to these alterations. Therefore, host, diet and immune system interactions should be evaluated in modulation of intestinal microbiota. In this review, the effect of gluten-free diet and microbiota-focused therapies on intestinal microbiota in pediatric celiac patients was evaluated.
\end{abstract}

Keywords: Celiac disease, microbiota, gluten free diet, child

\footnotetext{
" Bu çalışma, Gazi Üniversitesi, Bilimsel Araştırma Projeleri (BAP) birimi tarafindan 47/2019-02 proje numarası ile desteklenmiştir.

1. İletişim/Correspondence: Gazi Üniversitesi, Sağlık Bilimleri Fakültesi, Beslenme ve Diyetetik Bölümü, Ankara, Türkiye • E-posta: yasemnertas@gmail.com (1) https://orcid.org/0000-0002-8232-103X

2. Gazi Üniversitesi, Sağlık Bilimleri Fakültesi, Beslenme ve Diyetetik Bölümü, Ankara, Türkiye ৫ https://orcid.org/0000-0002-4210-1657
} 


\section{GİRIŞ}

Çölyak hastalığı, genetik olarak yatkınlığı bulunan bireylerde gluten ve ilişkili prolaminler tarafından tetiklenen ve glutene bağlı klinik semptomların varlığı ile karakterize immün-aracılı sistemik bir bozukluktur (1). Ülkemizde okul çağı çocuklarının tarandığı geniş örneklemli çalışmaya göre çölyak prevalansının \%0.47 olduğu gösterilmiş olsa da, prevalansın daha da yüksek (\%1.74) olabileceği tahmin edilmektedir (2).

Çölyak hastalığının patofizyolojisi halen net olarak bilinmemekle birlikte buğday, arpa, çavdar ve bu tahıllardan elde edilen ürünlerde bulunan glutenin tüketilmesini takiben gelişen bir dizi reaksiyonla hastalık tetiklenmektedir (3). Gluten, yapısında gliadin ve glutenin proteinlerini içerir. Bu proteinler özellikle prolin ve glutamin aminoasitlerinden zengindir (4). Bu proteinlerin yüksek prolin içerikleri gastrik ve pankreatik proteolitik enzimlere dayanıklıdır. Bunun sonucunda birçok sindirilemeyen 33-mer uzunluğundaki gliadin peptidi, çölyak hastalarında bağışıklık sistemini tetikler (5). Gliadinin bir kısmı enzimatik olarak glutamine, daha sonra lamina propriadaki doku transglutaminaz (tTG) tarafindan deamine edilerek glutamik asit rezidülerine çevrilir ve oluşan negatif yüklü moleküller adaptif immün sistemin aktifleşmesine neden olur. İmmünojenitesi artan deamine gliadin, insan lökosit antijeni (Human Leukocyte Antigen [HLA]) DQ2/8 moleküllerinin antijen sunan hücrelerine kolaylıkla bağlanır, $\mathrm{CD} 4^{+} \mathrm{T}$ hücreleri tarafından tanımlanır ve proinflamatuvar süreç başlar $(6,7)$.

Çölyak hastalığında en baskın genetik risk faktörleri, HLA Sinıf II moleküllerini kodlayan HLA-DQ2 ve HLADQ8 genotipleridir. Ancak her HLA-DQ pozitifliği olan bireyde çölyak hastalığı görülmez (8). Bu nedenle, çölyak hastalığının oluşumunda başka faktörlerin yer alabileceği ve intestinal mikrobiyotada oluşan disbiyozis ve konakçı mikrobiyom etkileşimlerinin hastalığın gelişiminde etkili olabileceği düşünülmektedir (3). Bu derleme yazıda, çocuk çölyak hastalarında glutensiz diyet ve mikrobiyota odaklı tedavilerin intestinal mikrobiyotaya etkisinin incelenmesi amaçlanmıştır.

\section{Çölyak Hastalığında Disbiyozis}

Gastrointestinal sistem, patojenik ve komensal bakteriler ile besin alerjenlerinin dahil olduğu birçok yabancı materyali içeren, dış çevreyle en fazla etkileşen, vücudun en geniş yüzeyini oluşturur (9). Aktif çölyak hastalığı olan ya da tedavi altındaki çocuklarda, kontrol grubuna göre mikrobiyota kompozisyonundaki farklılıklar ve kısa zincirli yağ asidi düzeylerindeki değişimler Tablo 1'de gösterilmiştir (10-22).

Yapılan çalışmalarda, çölyak tanısı alan ancak henüz tedavi almayan çocuklar ile belli bir süre glutensiz diyet tedavisi alan çocukların fekal ve duedonal mikrobiyota kompozisyonlarında farklı takson seviyelerinde ayrışmalar olduğu belirlenmiş ve hastalığın aktif döneminde potansiyel patojen mikroorganizmalarda artış, potansiyel yararlı türlerde ise azalmalar rapor edilmiştir (1022). Özellikle Lactobacillus ve Bifidobacterium türlerinde belirlenen değişimler çölyak hastalığında mikrobiyotanın modüle edilerek tedavisine yönelik potansiyel yöntemlerin olabileceğine işaret etmiştir (13-15,22).

\section{Glutensiz Diyetin Özellikleri ve İntestinal Mikrobiyota Üzerine Potansiyel Etkisi}

Çölyakhastalığınınetkinliğikanıtlanmıştektedavişekli glutensiz diyet tedavisidir. Tedavinin uygulanması oldukça zordur ve gluten içeren besin kaynaklarının diyetten çıkarılması diyet örüntüsünde değişiklere yol açtığından, diyetin besin ögesi yönünden dikkatlice planlanarak izlenmesi gerekmektedir. Hastalar diyetten çıkarılan buğday, arpa ve çavdar ile bunların işlenmesi sonucu elde edilen özellikle un, bulgur ve makarna gibi günlük hayatta yoğunlukla kullanılan besinlerin glutensiz eşdeğerlerini tüketmek durumundadır (23). Ayrıca bu besinlerden yaplan ekmek, kek, bisküvi, kurabiye gibi paketli ürünlerde yapının korunabilmesi amacıyla sıklıkla daha yüksek karbonhidrat ve yağ kullanımı söz konusudur $(24,25)$. Çölyak hastası olan çocuklar ve sağlıklı kontrollerin 
Tablo 1. Çocuk çölyak hastalarında mikrobiyota değişimlerinin özeti

\begin{tabular}{|c|c|c|}
\hline Referans ve yılı & Örnek şekli & Mikrobiyotada görülen değişimler \\
\hline Collado et al. (10) & Fekal örnek & $\begin{array}{l}\text { Aktif çölyak hastalığı olanlarda Bacteroides, Clostridium ve Staphylococcus } \\
\text { seviyelerinde artı̧ } \\
\text { Kontrollerde daha yüksek Bifidobacterium eğilimi }\end{array}$ \\
\hline Nadal et al. (11) & Duedonal biyopsi & $\begin{array}{l}\text { Çölyak hastalığı olanlarda total ve gram-negatif bakteri sayısı, Bacteroides ve } \\
\text { Escherichia coli daha yüksek }\end{array}$ \\
\hline Sanz et al. (12) & Fekal örnek & $\begin{array}{l}\text { Kontrolde Lactobacillus casei grubu çölyak hastalığı olanlara göre daha } \\
\text { yüksek ve Bifidobacterium popülasyonu daha çeşitli }\end{array}$ \\
\hline Collado et al. (13) & $\begin{array}{l}\text { Fekal örnek ve } \\
\text { duedonal biyopsi }\end{array}$ & $\begin{array}{l}\text { Çölyak hastalığı olanlarda total Bifidobacterium ve Bifidobacterium longum } \\
\text { düzeyleri daha düşük }\end{array}$ \\
\hline Collado et al. (14) & $\begin{array}{l}\text { Fekal örnek ve } \\
\text { duedonal biyopsi }\end{array}$ & $\begin{array}{l}\text { Çölyak hastalığı olanlarda Bacteroides ve Clostridium leptum grupları } \\
\text { Escherichia coli ve Staphylococcus sayıları daha yüksek } \\
\text { Tedavi sonrası Bifidobacterium seviyeleri kontrol ile benzer }\end{array}$ \\
\hline Di Cagno et al. (15) & Fekal örnek & $\begin{array}{l}\text { Çölyak hastalığı olanlarda Lactobacillus türlerinde düşüşler ve uçucu organik } \\
\text { bileşiklerde farklılıklar }\end{array}$ \\
\hline Schippa et al. (16) & Duedonal biyopsi & $\begin{array}{l}\text { Çölyak hastalığı olanlarda Bacteroides vulgatus ve Escherichia coli düzeyleri } \\
\text { daha yüksek }\end{array}$ \\
\hline Di Cagno et al. (17) & $\begin{array}{l}\text { Duedonal biyopsi ve } \\
\text { fekal örnek }\end{array}$ & $\begin{array}{l}\text { Çölyak hastalığı olanlarda Lactobacillus, Enterococcus ve Bifidobacteria } \\
\text { düzeyleri daha düşük } \\
\text { Tedavi alan hastalarda kontrole göre Bacteroides, Staphylococcus, Salmonella, } \\
\text { Shighella ve Klebsiella daha yüksek }\end{array}$ \\
\hline Sanchez et al. (18) & Fekal örnek & $\begin{array}{l}\text { Çölyak hastalığı olanlarda kontrole göre } B \text {. Fragilis en baskın, B. ovatus en az } \\
\text { baskın tür }\end{array}$ \\
\hline Sánchez et al. (19) & Duedonal biyopsi & $\begin{array}{l}\text { Çölyak hastalığı olanlarda Klebsiella oxytoca, Staphylococcus epidermidis, ve } \\
\text { Staphylococcus Pasteuri daha baskın, Streptococcaceae ailesi daha az baskın }\end{array}$ \\
\hline Tjellström et al. (20) & Fekal örnek & $\begin{array}{l}\text { Bir yıldan uzun süredir tedavi altında olan çocuklarda KZYA düzeyleri bir } \\
\text { ylldan daha kısa olanlardan farklı }\end{array}$ \\
\hline Wacklin et al. (21) & Duedonal biyopsi & $\begin{array}{l}\text { Hastalarda görülen gastrointestinal sistem veya ekstraintestinal semptomlara } \\
\text { göre mikrobiyota çeşitliliği ve filum düzeylerinde farklllıklar }\end{array}$ \\
\hline Olivares et al. (22) & Fekal örnek & $\begin{array}{l}\text { Çölyak tanısı alanlarda Firmicutes artışında duraksama, Bifidobacterium breve } \\
\text { ve Enterococcus düzeylerinde artış }\end{array}$ \\
\hline
\end{tabular}

KZYA: Kısa zincirli yă̆ asitleri

karşılaştırıldığı çalışmaların bir meta-analizinde, her iki grubun yağ alımlarının yüksek; posa, demir, kalsiyum ve D vitamini alımlarının yetersiz olduğu gösterilmiş, ancak glutensiz diyetle birlikte özellikle folat, magnezyum ve çinko alımının azaldığı, glisemik indeksi yüksek besinlerin tüketiminin ise arttığı gösterilmiştir (26).

Günümüzde beslenme şeklinin, özel besinlerin veya diyet bileşenlerinin bağırsak mikrobiyotasını modüle ettiği gösterilmiştir (27,28). Düşük posalı ve yüksek yağlı diyetlerin fekal bütirat sentezi de dahil kısa zincirli yağ asidi sentezinde ve Bifidobacterium türlerinde azalmaya sebep olduğu, bu değişimlerin inflamasyonu tetiklediği bildirilmiştir (28). Bu nedenle glutensiz beslenmenin de mikrobiyotayı etkileyebilecek bir etmen olarak düşünülmesi kaçınılmazdır (29). Ancak, glutensiz diyetler çölyak hastalığında tedavi olarak kullanılır ve tedavi ile birlikte bağırsak atrofisinde iyileşme görüldüğünden, mikrobiyota üzerine tek başına etkinliğini gözlemlemek kolay değildir (9). Bu nedenle literatürde glutensiz diyetlerin mikrobiyota üzerine etkisi çoğunlukla 4-8 hafta arasında değişen kısa süreli 
müdahale çalışmaları ile aydınlatılmaya çalışılmıştır (30-33). Literatürde sağlıklı çocuklarda yapılmış herhangi bir çalışma yer almadığından, bu bölümde sağllklı yetişkinlerde glutensiz diyet müdahalelerinin mikrobiyota üzerine etkinliği irdelenmiştir. Yapılan kısa süreli çalışmalar (4-8 hafta), glutensiz diyetlerin mikrobiyotada değişiklik yarattığını ve bu durumun diyet örüntüsündeki değişikliklere bağlı olarak gerçekleştiğini göstermektedir $(30,31)$. Buna göre nişasta metabolizmasında rol oynayan taksonlarda farklılıkların görüldüğü (30), ayrıca azalmış polisakkarit türlerinin Lactobacillus türleri, Bifidobacterium ve Bifidobacterium longum'da azalma, Escherichia coli ve toplam Enterobacteriaceae'da ise artmaya sebep olduğu ortaya konulmuştur (31). Öte yandan düşük glutenli beslenmenin bireylerin posa alımlarını değiştirmeden mikrobiyotaya etkisinin incelendiği bir çalışmada; Bifidobacterium, bütirat üreten Eubacterium hallii ve asetat üreten Blautia gibi taksonlarda düşüşler yaşandığı; ancak sekiz haftalık süre içerisinde immün sistemin proinflamatuvar sitokin salımını azalttığı bildirilmiştir (32). Bu çalışmada katılımcıların diyetlerinde yalnızca gluten azaltılmış, posa alımları ise kinoa, bezelye unu, yulaf, esmer pirinç, glutensiz çavdar unu gibi yüksek posa içeren özel ürünlerle (genellikle glutensiz barlar veya ekmek) korunması sağlanmıştır. $\mathrm{Bu}$ sebeple glutensiz diyetlerin çölyak hastalarında neden olduğu değişikliklerin posadaki değişimlerden kaynaklanabileceği görüşü ortaya atılmıştır (32). Bir diğer çalışmada ise glutensiz diyetlerde diyete prebiyotik eklemesinin Bifidobacterium sayısında ve fekal asetat ve bütirat düzeylerinde anlamlı artışlar sağladığı bulunmuştur (33). Dolayısıyla; glutensiz diyet planlanırken, gluten içeren diyete benzer posa niteliğine sahip olması için alternatif posa kaynaklarının (kinoa, amarant, karabuğday, kurubaklagil unları vb.) diyete eklenmesinin mikrobiyotayı modüle edebileceği düşünülmüştür.

\section{Mikrobiyota Odaklı Diğer Tedavi Yaklaşımları}

Glutensiz diyetler, çölyak hastalığının tedavisinde tek etkili tedavi olmasına rağmen günlük yaşamı kısıtladığından dolayı hastaların alternatif yöntemlere ilgi duymalarına yol açmaktadır $(34,35)$. $\mathrm{Bu}$ alternatif yöntemlerden biri de probiyotik tedavisidir. Özellikle Bifidobacterium longum CECT 7347 suşunun çocuklarda üç ay içerisinde glutensiz diyetin etkinliğini artırdığı, T lenfosit aktivasyonunu azalttığı ve inflamatuvar sürece olumlu etki gösterdiği bildirilmiştir (36). Bir diğer çalışmada, Bifidobacterium breve'nin diyet tedavisi altındaki çölyak hastalığı olan çocuklarda tümör nekrozis faktör alfa (TNF-a) düzeylerini azalttığı bildirilmiştir (37). Bifidobacterium breve BR03 ve Bifidobacterium breve B632 suşlarının bir arada verilmesi mikrobiyotanın düzelmesini sağlamıştır (38). Bifidobacterium breve BR03 ve Bifidobacterium breve B632 suşlarının eşit oranlarda karıştırılması ve karışımın üç ay süresince çocuklara verilmesinin ardından çölyak patogenezinde rolü olabileceği düşünülen ve antiinflamatuvar süreçte etkili yeni filumların varlığı gösterilmiştir (39). Bu sayede, ileride çölyak hastalığında fekal mikrobiyota transplantasyonu tedavisi gibi potansiyel bir başka tedavinin de kullanılabileceği ön görülmektedir (40).

\section{SONUÇ VE ÖNERİLER}

Çölyak, patogenezinde genetik, immün ve çevresel faktörlerin bir arada rol oynadığı kompleks bir hastalıktır. Çölyak hastası çocuklarda intestinal mikrobiyotanın değiştiği açıktır, ancak hastalığa özgü kesin bir mikrobiyota şeklinin tanımı henüz yapılamamıştır. Bunun muhtemel nedenleri çalışmaların farklı bireyler üzerinde yürütülmesi ve diyet bileşenlerinin çoğu zaman göz önünde bulundurulmaması olabilir. Sağlıklı çocuklarda glutensiz diyetlere yönelik herhangi bir çalışma bulunmamasına rağmen; sağlıklı yetişkin bireyler üzerinde yürütülen araştırmalarda bildirildiği gibi intestinal sistemde görülen disbiyozise, glutensiz diyetlerin değişen örüntüsünün de katkı verebileceği unutulmamalıdır. Az sayıda çalışma glutensiz diyetlerin doğru planlandığı ve özellikle posadan zengin tutulduğu takdirde mikrobiyotanın modüle edilebileceğine dair ipuçları vermektedir. Yine de çocuk çölyak hastalarında mikrobiyota değişimlerinin 
aynı hasta üzerinde diyetin bileşenlerinin de göz önüne alınarak irdelendiği daha fazla çalışma ile bu görüşün desteklenmesine ihtiyaç bulunmaktadır. Son ylllarda, mikrobiyotayı hedef alan özellikle probiyotik müdahalelerinin çocuklarda denendiği ve ileride potansiyel tedavi yöntemi olarak kullanılabileceği düşünülmektedir.

Çıkar çatışması - Conflict of interest: Yazarlar çıkar çatışması olmadığın beyan ederler. - The authors declare that they have no conflict of interest.

\section{KAYNAKLAR}

1. Husby S, Koletzko S, Korponay-Szabo I, Mearin M, Phillips A, Shamir R, et al. European Society for Pediatric Gastroenterology, Hepatology, and Nutrition guidelines for the diagnosis of coeliac disease. J Pediatr Gastroenterol Nutr. 2012;54(1):136-60.

2. Dalgic B, Sari S, Basturk B, Ensari A, Egritas O, Bukulmez A, et al. Prevalence of celiac disease in healthy Turkish school children. Am J Gastroenterol. 2011;106(8):1512-7.

3. Chander AM, Yadav H, Jain S, Bhadada SK, Dhawan DK. Cross-talk between gluten, intestinal microbiota and intestinal mucosa in celiac disease: Recent advances and basis of autoimmunity. Front Microbiol. 2018;9:2597.

4. Lindfors K, Ciacci C, Kurppa K, Lundin KEA, Makharia GK, Mearin ML, et al. Coeliac disease. Nat Rev Dis Primers. 2019;5(1):3.

5. Shan L, Molberg Ø, Parrot I, Hausch F, Filiz F, Gray GM, et al. Structural basis for gluten intolerance in celiac sprue. Science. 2002;297(5590):2275-9.

6. Lebwohl B, Sanders DS, Green PH. Coeliac disease. The Lancet. 2018;391(10115):70-81.

7. Kagnoff MF. Overview and pathogenesis of celiac disease. Gastroenterology. 2005;128(4):S10-S18.

8. Rossi M, Schwartz KB. Celiac disease and intestinal bacteria: not only gluten? J Leukoc Biol. 2010;87(5):74951.

9. Verdu EF, Galipeau HJ, Jabri B. Novel players in coeliac disease pathogenesis: role of the gut microbiota. Nat Rev Gastroenterol Hepatol. 2015;12(9):497-506.

10. Collado MC, Calabuig M, Sanz Y. Differences between the fecal microbiota of coeliac Infants and healthy controls. Curr Issues Intest Microbiol. 2007;8(1): 9-14.

11. Nadal I, Donat E, Ribes-Koninckx C, Calabuig M, Sanz Y. Imbalance in the composition of the duodenal microbiota of children with coeliac disease. J Med Microbiol. 2007;56(Pt 12):1669-74.

12. Sanz Y, Sanchez E, Marzotto M, Calabuig M, Torriani S,
Dellaglio F. Differences in faecal bacterial communities in coeliac and healthy children as detected by PCR and denaturing gradient gel electrophoresis. FEMS Immunol Med Microbiol. 2007;51(3):562-8.

13. Collado MC, Donat E, Ribes-Koninckx C, Calabuig M, Sanz Y. Imbalances in faecal and duodenal Bifidobacterium species composition in active and non-active coeliac disease. BMC Microbiol. 2008;8:232.

14. Collado MC, Donat E, Ribes-Koninckx C, Calabuig M, Sanz Y. Specific duodenal and faecal bacterial groups associated with paediatric coeliac disease. J Clin Pathol. 2009;62(3):264-9.

15. Di Cagno R, Rizzello CG, Gagliardi F, Ricciuti P, Ndagijimana M, Francavilla $\mathrm{R}$, et al. Different fecal microbiotas and volatile organic compounds in treated and untreated children with celiac disease. Appl Environ Microbiol. 2009;75(12):3963-71.

16. Schippa S, Iebba V, Barbato M, Di Nardo G, Totino V, Checchi MP, et al. A distinctive 'microbial signature' in celiac pediatric patients. BMC Microbiol. 2010;10:175.

17. Di Cagno R, De Angelis M, De Pasquale I, Ndagijimana M, Vernocchi P, Ricciuti P, et al. Duodenal and faecal microbiota of celiac children: molecular, phenotype and metabolome characterization. BMC Microbiol. 2011;11:219.

18. Sanchez E, Laparra JM, Sanz Y. Discerning the role of Bacteroides fragilis in celiac disease pathogenesis. Appl Environ Microbiol. 2012;78(18):6507-15.

19. Sanchez E, Donat E, Ribes-Koninckx C, Fernandez-Murga ML, Sanz Y. Duodenal-mucosal bacteria associated with celiac disease in children. Appl Environ Microbiol. 2013;79(18):5472-9.

20. Tjellstrom B, Hogberg L, Stenhammar L, FalthMagnusson K, Magnusson KE, Norin E, et al. Faecal short-chain fatty acid pattern in childhood coeliac disease is normalised after more than one year's glutenfree diet. Microb Ecol Health Dis. 2013;24.

21. Wacklin P, Kaukinen K, Tuovinen E, Collin P, Lindfors K, Partanen J, et al. The duodenal microbiota composition of adult celiac disease patients is associated with the clinical manifestation of the disease. Inflamm Bowel Dis. 2013;19(5):934-41.

22. Olivares M, Walker AW, Capilla A, Benítez-Páez A, Palau F, Parkhill J, et al. Gut microbiota trajectory in early life may predict development of celiac disease. Microbiome. 2018;6(1):36.

23. See JA, Kaukinen K, Makharia GK, Gibson PR, Murray JA. Practical insights into gluten-free diets. Nat Rev Gastroenterol Hepatol. 2015;12(10):580-91.

24. Bascunan KA, Vespa MC, Araya M. Celiac disease: understanding the gluten-free diet. Eur J Nutr. 2017;56(2):449-59. 
25. Melini V, Melini F. Gluten-Free Diet: Gaps and needs for a healthier diet. Nutrients. 2019;11(1):170.

26. Di Nardo G, Villa MP, Conti L, Ranucci G, Pacchiarotti C, Principessa L, et al. Nutritional deficiencies in children with celiac disease resulting from a gluten-free diet: A systematic review. Nutrients. 2019;11(7).

27. Simpson HL, Campbell BJ. Dietary fibre-microbiota interactions. Aliment Pharmacol Ther. 2015;42(2):15879.

28. Scott KP, Gratz SW, Sheridan PO, Flint HJ, Duncan SH. The influence of diet on the gut microbiota. Pharmacol Res. 2013;69(1):52-60.

29. Sanz Y. Microbiome and gluten. Ann Nutr Metab. 2015;67(Suppl. 2):27-42.

30. Bonder MJ, Tigchelaar EF, Cai X, Trynka G, Cenit MC, Hrdlickova B, et al. The influence of a short-term glutenfree diet on the human gut microbiome. Genome Med. 2016;8(1):45.

31. Sanz Y. Effects of a gluten-free diet on gut microbiota and immune function in healthy adult humans. Gut Microbes. 2010;1(3):135-7.

32. Hansen LB, Roager HM, Søndertoft NB, Gøbel RJ, Kristensen M, Vallès-Colomer M, et al. A low-gluten diet induces changes in the intestinal microbiome of healthy Danish adults. Nat Commun. 2018;9(1):4630.

33. Drabinska N, Jarocka-Cyrta E, Markiewicz LH, KrupaKozak U. The effect of oligofructose-enriched inulin on faecal bacterial counts and microbiota-associated characteristics in celiac disease children following a gluten-free diet: Results of a randomized, placebocontrolled trial. Nutrients. 2018;10(2).
34. Leinonen H, Kivela L, Lahdeaho ML, Huhtala H, Kaukinen K, Kurppa K. Daily life restrictions are common and associated with health concerns and dietary challenges in adult celiac disease patients diagnosed in childhood. Nutrients. 2019;11(8).

35. Imran Aziz, Kate E Evans, Vasiliki Papageorgiou, Sanders DS. Are patients with coeliac disease seeking alternative therapies to a gluten-free diet? J Gastrointestin Liver Dis. 2011;20(1):27-31.

36. Olivares M, Castillejo G, Varea V, Sanz Y. Double-blind, randomised, placebo-controlled intervention trial to evaluate the effects of Bifidobacterium longum CECT 7347 in children with newly diagnosed coeliac disease. Br J Nutr. 2014;112(1):30-40.

37. Klemenak M, Dolinšek J, Langerholc T, Di Gioia D, Mičetić-Turk D. Administration of Bifidobacterium breve decreases the production of TNF-a in children with celiac disease. Dig Dis Sci. 2015;60(11):3386-92.

38. Quagliariello A, Aloisio I, Bozzi Cionci N, Luiselli D, D’Auria G, Martinez-Priego L, et al. Effect of Bifidobacterium breve on the intestinal microbiota of coeliac children on a gluten free diet: a pilot study. Nutrients. 2016;8(10):660.

39. Primec M, Klemenak M, Di Gioia D, Aloisio I, Cionci NB, Quagliariello A, et al. Clinical intervention using Bifidobacterium strains in celiac disease children reveals novel microbial modulators of TNF- $a$ and shortchain fatty acids. Clin Nutr. 2019;38(3):1373-81.

40. Golfeyz S. Celiac disease and fecal microbiota transplantation: A new beginning? Am J Gastroenterol. 2018;113(8):1256. 